\title{
Presença da Igreja na construção da Paz
}

\author{
Luiz Antônio Pereira Lopes ${ }^{1}$
}

Gostaria de começar esse artigo partindo de dois pensamentos. O primeiro, a evangelização em áreas de conflitos só será possível por uma presença permanente nessas áreas, em outras palavras uma evangelização de proximidade. O segundo, como a lgreja pode criticar a ausência do Estado se ela eventualmente proceder da mesma forma? Infelizmente a presença do Estado nessas áreas tem sido somente a da polícia, não para pacificar e sim para reprimir. O Estado tem uma grande dívida social com os pobres. A questão da construção da paz de que eles necessitam, só poderá ser adequadamente compreendida numa perspectiva cristã, abordando-se alguns aspectos fundamentais, que indico a seguir.

a) Considerando Jesus presente no meio dos pobres e se fazendo pobre com os pobres. É o próprio Cristo que pede para que seus seguidores vejam nos pequenos e pobres a sua imagem.

" 'Vinde, benditos de meu Pai! Recebei em herança o Reino que meu Pai vos preparou desde a criação do mundo! Pois eu estava com fome e me destes de comer; estava com sede e me destes de beber; eu era forasteiro e me recebestes em casa; estava nu e me vestistes; doente, e cuidastes de mim; na prisão, e fostes visitar-me'. Então os justos lhe perguntarão: 'Senhor, quando foi que te vimos com fome e te demos de comer? Com sede e te demos de beber? Quando foi que te vimos como forasteiro e te recebemos em casa, sem roupa e te vestimos? Quando foi que te vimos doente ou preso e fomos te visitar?' Então o Rei lhes responderá: 'Em verdade vos digo: todas as vezes que fizestes isso a um destes mais pequenos, que são meus irmãos, foi a mim que o fizestes. "(Mt 25, 34-40)

b) Considerando a opção da Igreja pelos pobres

Na Conferência de Aparecida foi reafirmada a opção pelos pobres e excluídos. "Nos pobres, a dignidade humana está profanada. A opção pelos pobres é um dos traços que marca a fisionomia da Igreja no Continente (391). Ela está implícita na fé cristológica, naquele Deus que se fez pobre por nós, para nos enriquecer com sua pobreza (392). Por isso, somos chamados a contemplar, nos rostos sofridos de nossos irmãos, o rosto de Cristo que nos chama a servi-lo neles"....(393) - (Documento de Aparecida)

c) Considerando a missão dos leigos e leigas na Igreja e na Sociedade

"Viver o Evangelho, servindo as pessoas e a sociedade, promovendo a dignidade da pessoa humana, venerando e defendendo o inviolável direito à vida, transformando a família no primeiro espaço de engajamento social, sendo a caridade, alma e sustentáculo da solidariedade, sendo destinatários e protagonistas da política, pondo o

\footnotetext{
${ }^{1}$ Luiz Antônio Pereira Lopes é Monsenhor, é o Coordenador Diocesano da Pastoral de Favelas desde 1985. Palestra proferida na VII Semana da Cultura Religiosa, 16 de setembro de 2015, que teve como tema central: Políticas Públicas na cidade do Rio, "Paz e Esperança se abraçarão".
} 
homem no centro da vida econômico social, evangelizando a cultura e as culturas do homem." (CNLB)

d) Considerando a paz como fruto da justiça

"A paz é, antes de tudo, obra da justiça. Ela supõe e exige a instauração de uma ordem justa, na qual as pessoas possam realizar-se como seres humanos, sua dignidade ser respeitada, suas legítimas aspirações serem satisfeitas, seu acesso à verdade reconhecido, sua liberdade pessoal garantida. Uma ordem na qual os homens não sejam objetos, senão agentes de sua própria história. A tranquilidade da ordem, da paz, não é, pois, passividade nem conformismo." Dom Moacyr José Vitti CSS.

Levando em conta estas considerações apresentamos um pequeno histórico da Pastoral de Favelas da Arquidiocese do Rio de Janeiro, com seus objetivos, sua espiritualidade e desafios a serem vencidos.

\section{I - Histórico}

Trabalhar com os pobres a Igreja sempre trabalhou, basta ver na história, exemplos como: São Francisco de Assis, Santo Antônio de Padua, São Vicente, Beata Teresa de Calcutá e Beata Dulce etc. A preocupação com os moradores de favela, no Rio de Janeiro, vem desde 1946, quando a Arquidiocese do Rio de Janeiro criou a Fundação Leão XIII para estar presente nas favelas, assim foi por muitos anos. Com a divulgação do trabalho realizado e muita publicidade, aquelas ações iniciais acabaram servindo a interesses contrários e colaborando com a remoção de favelas. A Igreja, então, abriu mão da Fundação e o Estado assumiu esta instituição.

Na década de 50, Dom Hélder Câmara, então, Bispo Auxiliar do Rio de Janeiro, retomou a conscientização em larga escala, dentro e fora da lgreja, denunciando o escândalo da habitação popular no Rio de Janeiro. Como ação concreta criou a Cruzada São Sebastião, cujo método de trabalho consistia, principalmente, em investir na pessoa humana do favelado, assessorando-o tecnicamente e organizando-o em comitês - verdadeiros embriões das atuais Associações de Moradores de Favelas - tendo executado 53 projetos de rede e luz, urbanizando a favela Parque da Alegria, ao longo da Avenida Brasil e, parcialmente, a favela do Morro Azul, no Flamengo. Fez construir nas proximidades da Praia do Pinto edifícios com 910 apartamentos (Cruzada São Sebastião) e interferiu contra as tentativas de despejos nos morros do Borel (1958), Esqueleto e Santa Marta (1959).

$\mathrm{Na}$ década de 60, alternada a situação política do País, o trabalho se setoriza e regionaliza, numa perspectiva mais doméstica, passa a se fundamentar nas Paróquias ou em Grupos de Igreja, locais onde se fortificou por mais de 10 anos. Em 1976, sob a Coordenação do Pe. Ítalo Botelho, a pastoral de favelas desenvolveu um trabalho social no Morro dos Cabritos em Copacabana; na área Oeste, atuava o Pe. João Cribbim, com o grupo terra e habitação; na área Norte, atuava o Pe. Mario Prigol; na Leopoldina, o Pe. Carlos; na 
Suburbana, Pe. Franklin. Todos os grupos que atuavam em favelas passaram a se reunir para troca de experiências, desenvolvendo o trabalho em dimensão de toda a cidade. Estes encontros - Assembleias de Pastoral -, realizados inicialmente na Zona Sul, se propagaram posteriormente nos demais vicariatos, com o objetivo específico de agilizar a troca de experiências e conjugar os esforços na descoberta de caminhos para a luta comum. Desses encontros ressurgiu a força das Associações de Moradores e da Federação das Associações de Favelas do Rio de Janeiro - FAFERJ - que infelizmente, durante certo período, não representou bem o movimento. Servia a interesses não condizentes com a real aspiração e as necessidades do movimento popular.

Ainda nos anos 70, após memorável eleição presidida pela Seccional do Rio de Janeiro da OAB, foi vencedora na diretoria da FAFERJ uma chapa integrada por líderes com posições políticas diversas, mais representativas do quadro do movimento popular, onde estavam presentes moradores de favela participantes do trabalho da Pastoral. Impõe-se então, como tarefa urgente, a sustentação do trabalho da nova diretoria da Federação.

O serviço jurídico da Pastoral foi institucionalizado em meados de 1977, a partir do "Caso Vidigal", no qual os advogados Sobral Pinto, Bento Rubião, Eliana Athayde e Maria Alice Adão Antunes tiveram uma brilhante atuação. Sentiram a necessidade de fortalecer a atividade preventiva de consultoria, com visitas locais, antecipando situações de risco e impedindo a desmobilização da Federação.

Na década de 80, a Pastoral das Favelas se empenhou na criação e no fortalecimento das Associações de Moradores, na conscientização do direito à cidadania e participação popular como forma de transformação da sociedade. Foram realizados estudos para efetivar conquistas e direitos nas novas constituições Federal, Estadual e Municipal. Alguns parágrafos da nova legislação foram elaborados com uma efetiva ajuda da Pastoral de Favelas, que enviou propostas de emenda populares e apoiou a mobilização das favelas.

Por iniciativa de Dom Eugenio de Araújo Sales, a própria residência do cardeal foi palco, nessa época, de memoráveis encontros com os líderes das favelas, que tiveram a oportunidade de ficar frente-a-frente com o Governador, o Prefeito do Rio de Janeiro, Secretários e políticos, em busca de soluções para o problema habitacional desta cidade.

$\mathrm{Na}$ década de 90, concentramos nossos esforços no diálogo com as ONGs e com os Poderes Públicos (Executivo, Judiciário e Legislativo). Além disso, ampliamos o espaço para atuação da lgreja nas favelas. Grande esforço foi feito para manter em cada favela uma Capela, um Centro Comunitário ou uma Creche como ponto de celebrações e de reuniões para debates dos problemas locais.

Buscamos a superação do abismo existente entre o poder Público e a carência de nossas Favelas, visando a valorização e a promoção do Ser Humano que é imagem e semelhança de Deus (cf. Gn 1,27). Para melhor atuação da Pastoral e dos Agentes passamos 
a organizar cursos de formação, encontros e participações em fóruns populares, cooperativas, seminários que se estendem até o momento atual.

Em 2000, ao mesmo tempo em que festejávamos o Jubileu de Nosso Senhor Jesus, ficamos tristes com o enfraquecimento dos movimentos populares. As grandes lideranças populares foram ocupar cargos públicos. As ONGs passaram a trabalhar como OSCIP (Organização da Sociedade Civil de Interesse Público), ou como prestadoras de serviço terceirizadas, contratadas pelos órgãos públicos. As associações de moradores, na sua grande maioria, não representavam mais os anseios das comunidades. Tal como se fez no passado, a Pastoral de Favelas constitui-se, nos dias atuais, como espaço de vez e voz para os moradores das favelas.

Por ter grande capilaridade e certa independência em relação às disputas políticopartidárias, a Igreja permanece identificada com a realidade local das favelas do Rio de Janeiro. Desse modo, o trabalho pastoral da Igreja nessas comunidades se constitui como um instrumento de reivindicação para aqueles sem vez e sem voz.

Sem deixar de lado o dever do Estado; buscamos diálogo com o Judiciário (Ministério Público e a Defensoria Pública), o Legislativo (Parlamentares - Deputados e Vereadores) e o Executivo ( Governador e Prefeito). Reconhecemos que a adesão foi mais assumida por parte de alguns membros, do que pelas instituições em geral. Com o apoio da Pastoral de Favelas, foi criado nesta época o Conselho Popular, composto por representantes das diversas favelas, técnicos, assessores de parlamentares; tendo o compromisso de encaminhar as demandas ao Poder Público.

Nos anos 2011 e 2012 - produzimos e exibimos para às favelas um DVD, documentário, mostrando o trabalho desenvolvido pela Pastoral de Favelas nesses 35 anos de existência.

Nos anos 2013 e 2015 - continuamos trabalhando na defesa de uma moradia digna para as populações mais pobres desta cidade. Com os Mega Eventos como: Copa do Mundo e as Olimpíadas, foram construídas várias vias, em toda a cidades. A chamada "internacionalização da cidade" causou muitos despejos, com remoções e indenizações a baixo custo do poder público. Muitos embates aconteceram e a pastoral de favelas agiu como "advogada da justiça e defensora dos pobres diante das intoleráveis desigualdades sociais e econômicas, que clamam ao céu" (Documento de Aparecida,395).

\section{II - Objetivos}

Diante da realidade atual, hoje com um déficit habitacional de 350 mil moradias na cidade do Rio de Janeiro, nossos objetivos assumem dimensões proféticas e transformadoras.

\section{Objetivos Gerais:}


1. Ser presença - enquanto comunidade de Fé no mundo marginalizado, nas favelas e periferias - Como Igreja, é de grande valia e urgente a nossa presença não só uma presença física, mas também solidária, que sofre com os fracos. (Cf. 1Cor 9,22)

2. "Ser estímulo à organização e conscientização das comunidades buscando "integrar mundos sociais diversos e diminuir os abismos da separação". (João Paulo II, Vidigal, 1980) - É sempre um grande desafio superar a barreira dos dois mundos. Mundos diversos com culturas e hábitos diferentes. A cultura do asfalto não pode invadir as favelas criando hábitos e costumes, que o pobre não pode alimentar. Vivemos numa sociedade que atrapalha o desenvolvimento dos mais pobres criando neles necessidades fora de sua realidade, um mundo imaginário que se torna real à custa da violência ou um sacrifício desnecessário. Há uma necessidade de integrar os dois mundos sem violentar o direito dos mais pobres. Não são duas cidades dentro de uma só, mas uma única cidade que deve assumir e respeitar culturas ou hábitos diferentes.

\section{Amadurecer o compromisso social dos cristãos, ajudando-os a perceber seu papel} como sujeito na transformação da sociedade - Por mais que se oriente, há sempre uma parcela de cristãos que não querem se envolver com as questões sociais e políticas, preferem muitas vezes viver uma espiritualidade desencarnada e fora de um compromisso com o social. Não acreditam que a transformação passe por suas mãos, não se consideram sujeitos da história.

4. Trabalhar com o povo e não para o povo - Ainda existe em nós um jeito paternalista de ser. Achamos que devemos resolver pelos outros e não com os outros. A paciência histórica faz com que o outro cresça e nos leva também ao crescimento.

\section{Utilizar critérios de discernimento para o incentivo ao compromisso sociopolítico -}

Devemos agir à luz dos ensinamentos de Cristo e de suas atitudes, percebendo que ele assume o mistério da encarnação com todas as suas consequências. (Cf. Fil 2,7-8)

\section{Objetivo Específicos:}

a) Agilizar a troca de experiências e a conjugação de esforços à descoberta de caminhos para a luta comum - a cada dia na vida aprendemos coisas novas com os outros. O que sabemos passamos adiante, somando forças com outras instituições da sociedade, no intuito de encontrar caminhos novos para o bem comum. A soma de nossas experiências nos fortalece para o crescimento comum. 
b) Caminhar juntos unidos pela Fé no evangelho, pela esperança e perseverança, lutando pela justiça e pelo Amor Fraterno - como cristãos, tendo sempre Cristo como modelo, caminhamos juntos pela fé acreditando que o amor fraterno nos ajudará a construir uma sociedade mais justa.

c) Levar as pessoas e os grupos sociais à tomada de consciência de sua dignidade e ao compromisso de renovação de sua vida e da sociedade - através da vivência do Evangelho, da vivência da justiça, da solidariedade humana, da participação na comunidade eclesial, desejamos prestar um serviço aos cristãos engajados, no sentido de conscientizá-los a uma participação mais ativa na sociedade civil e animá-los a ser fermento e luz no meio do povo. Somos convidados por Cristo a sermos Sal da terra e Luz do mundo (Cf. Mt 5,14-16).

d) Favorecer o amadurecimento do compromisso social dos cristãos e ajudá-los a perceber qual deve ser o seu papel, frente à problemática social - não somos objetos da história, mas sujeitos. Na criação do mundo, Deus diz: "Façamos o homem e a mulher a nossa imagem e semelhança, que eles dominem os peixes do mar, as aves do céu, os animais domésticos, todas as feras e todos os répteis que se arrastam sobre a terra". (Gn 1,26-28). Somos os grandes colaboradores de Deus, co-criadores.

e) Fazer da Fé o princípio inspirador e alimentador do cristão no compromisso com a libertação do povo - "(...) para que todos os aspectos da vida social onde se manifesta a injustiça sofram uma transformação para a justiça" (João Paulo II, Corcovado, Rio de Janeiro, 1980). As pessoas devem ter a consciência cada vez mais clara da dignidade do homem em sua visão cristã.

\section{IV- Espiritualidade da Pastoral de Favelas}

Nos trabalhos da Pastoral, os fiéis se reúnem para rezar e celebrar, para criar consciência e entendimento, para discutir os seus problemas e os das comunidades; também para um compromisso comum em mudar as suas vidas para melhor, tudo isso inspirado e acompanhado por Deus.

A sociedade atual precisa ser "re-humanizada" e, assim, permitir que todos vivam na dignidade que Deus doou a cada um. Precisamos construir uma nova civilização, a civilização do amor, que pode ser a expressão daquilo que o Papa Francisco tem insistido, quando fala de "uma Igreja pobre para os pobres". O amor significa desapego e, assim, somos chamados a "sermos pobres" para poder amar de verdade e construir esta civilização do amor.

A Espiritualidade - se for autêntica - é, antes de tudo, Espiritualidade Humana. Ser espiritual significa ser "humano", viver o "humano" (a "humanidade") sempre mais radicalmente, libertando-se de tudo aquilo que oprime e desumaniza. "O pecado diminui o ser humano, 
impedindo-o de conseguir a plenitude" (Concílio Vaticano II. A Igreja no mundo de hoje - GS, 13). Nunca o ser humano exagera em ser "humano", nunca o ser humano é "humano" demais. Jesus de Nazaré é o maior exemplo de radicalidade humana e de vivência do "humano".

Se queremos ser homens e mulheres espirituais (de Espiritualidade), sejamos humanos, radicalmente humanos, em todos os momentos e em todas as situações da vida, mesmo e sobretudo nas situações que ainda são desumanas.

A Espiritualidade Humana, à luz da fé, é Espiritualidade Cristã. Não são duas Espiritualidades diferentes. É a mesma Espiritualidade. A Espiritualidade não pode ser cristã se não for humana e, se for humana, é - implícita ou explicitamente - cristã.

A fé é como um farol que ilumina a razão humana, amplia seus horizontes e a torna capaz de enxergar melhor e mais longe. Em outras palavras, a fé dá à razão humana as condições de compreender - sempre mais profunda e radicalmente - o ser humano. Em Jesus Cristo, o "humano" é tão humano que se torna "divino" e o "divino" é tão divino que se torna "humano".

Por ser Cristo "a chave, o centro e o fim de toda a história humana" (GS, 10),

"o mistério do ser humano (homem e mulher) só se torna claro verdadeiramente no mistério do Verbo encarnado. Com efeito, Adão o primeiro homem era figura daquele que haveria de vir, isto é, de Cristo Senhor. Novo Adão, na mesma revelação do mistério do Pai e de seu amor, Cristo manifesta plenamente o ser humano ao próprio ser humano e Ihe descobre a sua altíssima vocação" (GS, 22).

Assim sendo, devemos seguir Jesus Cristo Evangelizador dos pobres. Na sua relação com os pobres, Jesus Cristo vai revelando o mistério da Encarnação. A Encarnação de Cristo e servidor dos pobres, para eles Jesus revela o rosto misericordioso de Deus. Cristo manifestou claramente o amor apaixonado que Deus tem para com o ser humano e especialmente com os Pobres, os menos amados, devido à situação de pobreza vulnerabilidade, de fragilidade, de marginalidade ou de exclusão.

É preciso revestir-se dos sentimentos e atitudes de Cristo e agir como ele agiu. Vemos esta atitude em Santos da Igreja como Francisco de Assis, Vicente de Paulo, Beata Madre Teresa de Calcutá - Sabem que o verdadeiro amor conjuga o amor de Deus e aos Pobres. "Amemos a Deus meus irmãos, com a força de nosso braço e o suor de nosso rosto." (São Vicente de Paulo - Coste, XI, 40).- É preciso revestir-se dos sentimentos e das atitudes de Cristo e viver concretamente os ensinamentos d’Ele.

\section{V-Desafios:}

Em nossas atividades nos deparamos com muitos desafios queremos apresentar alguns deles, lamentavelmente presentes há anos no dia-a-dia de nossas comunidades. 
1. Driblar a realidade de violência - Diante da realidade de violência, seguindo os ensinamentos dos primeiros cristãos quando eram perseguidos pelo império romano e foram anunciar nas catacumbas, hoje vivemos realidades semelhantes em tempo de perseguição e de balas perdidas. Temos que "entrar nas catacumbas". Devemos aproveitar, cada vez mais, os agentes locais da própria comunidade que conhecem bem a realidade local e são conhecidos na comunidade. Valorizar os agentes da própria comunidade é fundamental, para o desenvolvimento de nossos trabalhos, ainda mais quando a violência toma conta da cidade. Em tempos de violência isto é fundamental.

2. Criar lideranças apartidárias ou sem envolvimento direto com os partidos políticos - Nosso trabalho não é apolítico e nem político partidário, mas devemos estar sempre incentivando as pessoas e as comunidades a terem envolvimento político. Essa "é a forma de podermos praticar a caridade, pois por meio dela podemos fazer o bem a muitas pessoas". (Texto-base CF 1996, no 111). Nos compreendemos apartidários pois, como lgreja, nosso trabalho eclesial não tem partido político. Fazemos parcerias com entidades, movimentos, etc., que trabalham para o bem comum, contanto que respeitem os nossos princípios cristãos.

3. Reunir às comunidades - Acreditamos na força da organização popular, da união, etc. Nos últimos anos, com a cooptação das lideranças comunitárias por parte do poder público ou das ONGS, com a presença da violência, por lutarem tanto e não verem as coisas melhorarem, as pessoas perderam o estímulo para se reunirem. Temos a certeza de que é o Reino que queremos , anunciamos e buscamos, mas é "no já e no ainda não" é que buscamos. O reino é feito de pequenas conquistas ainda aqui. Devemos viver aqui já os sinais do Reino de Deus.

4. Constante cobrança da comunidade junto ao poder público - É dever do Estado garantir os direitos fundamentais do ser humano como diz o artigo 25 da Declaração Universal dos Direitos humanos: "Todo homem tem direito a um padrão de vida capaz de assegurar a si e à sua familia, saúde e bem-estar, inclusive, alimentação, vestuário, habitação" (cf. Eclo 29,21-28). Cabe à comunidade exigir do poder público, a garantia dos seus direitos.

Com frequência, vemos o poder público afastado das comunidades. Eles trancam as porta, e só voltam a abri-las na hora das eleições porque precisam se manter no poder, mas no dia a dia não querem saber das comunidades.

"Ao ocupar-nos dessa realidade nacional, estamos fazendo numa atitude de Serviço, como pastores, para que haja maior participação nos bens de toda ordem para todos." (Puebla, 1255).

5. Integrar Fé e Vida - Segundo o apóstolo Tiago, a fé sem obras é morta (cf. Tg 2,14-26). Nossa Pastoral deve ter sempre um olho voltado para Deus e outro para o próximo. É isto que 
nos diferencia das diversas ONGS ou do chamado o terceiro setor. Nós somos um grupo de fé, não é possível chegar a Deus sem amar o próximo. Os mais sofridos desta cidade nos levam a Deus através de seu testemunho de vida e da sua esperança. Não podemos, de nenhuma forma, separar o primeiro mandamento (amar a Deus) do segundo mandamento (amar o próximo).

6. Superar a visão da Pastoral como "corpo de bombeiro", emergencial - Um trabalho pastoral não pode ser ocasional, ou esporádico, ele deve ser permanente. É um trabalho evangelizador. É sempre um desafio estarmos reunidos para discutir e encontrar soluções para os problemas que afetam às comunidades. Queremos respostas imediatas e soluções mágicas. Quando se trata de uma Pastoral nossos olhares não podem ser só para o agora, mas sim para o amanhã, para as gerações futuras. "O novo céu e a nova terra" começam já no aqui e agora da vida das pessoas, tendo seu prolongamento na "Jerusalém celestial" (cf. 2 Pd 3,13).

7. Superar a baixa estima - Os pobres estão sempre se esforçando: trabalham, estudam, moram longe, cuidam da família etc. O Estado e a sociedade tratam com preconceito. As chances de crescimento humano e social estão se tornando cada vez mais difíceis. Tudo para o pobre, ou um morador de favela é difícil. Tem que negar - esconder o seu endereço para conseguir um emprego. Eles sofrem com tudo isso e quem abraça essa causa sofre também em solidariedade.

Os pobres não estão livres desses preconceitos impostos pela sociedade que acabam atrapalhando a ação cidadã. Esta ação pressupõe uma participação ativa e deve estar comprometida com o desenvolvimento do grupo social.

Munidos de solidariedade, companheirismo e capacidade de servir ao outro, podemos ir em busca do bem comum e nos esforçar na promoção do bem público. O talento individual somado com o coletivo se completam. As necessidades humanas são comuns a todos: trabalho, educação, saúde, transporte, lazer, habitação... (Artigo 25 da Declaração dos Direitos Universais do Homem; e Eclo 29,21-28). É tempo de participação, integração. É muito importante que todos nós saibamos dizer não ao isolamento e à segregação.

\section{Concluindo}

O trabalho da Pastoral de Favelas não se resume às celebrações litúrgicas nas favelas, mas de cuidar das pessoas como um todo, preparar as pessoas para a vida (social, religiosa e política). Não separamos o primeiro mandamento - "Amarás o Senhor, teu Deus, com todo o teu coração, com toda a tua alma e com todo o teu entendimento" - do segundo mandamento "Amarás teu próximo como a ti mesmo" (Mt 22, 37-38). Como rezar se eu não tenho o mínimo necessário para a vida? Com fome ninguém consegui rezar ou fazer qualquer outra atividade . Ou como diz São Tiago “ Assim também a fé: se não se traduz em ações, por si só está morta “ 
$(\operatorname{Tg} 2,17)$. Termino este pequeno trabalho como comecei : a Igreja tem que ser presença no meio dos pobres. 